\title{
Overcoming sampling issues in dental tribology: Insights from an experimentation on sheep
}

\author{
Anusha Ramdarshan, Cécile Blondel, Denis Gautier, \\ Jérôme Surault, and Gildas Merceron
}

\begin{abstract}
Dental microwear has been used in paleoecology for nearly half a century. The advent of technologies in the past decade has allowed for enamel surfaces to be scanned in 3D, and thus for microwear textures to be characterized as a whole. Although dental microwear texture analysis is widely used, few studies have tackled the issue of sample representativity, or the variability of the microwear signal along a facet or a tooth row. How much information can we accurately extract from a fossil sample when tooth wear is considered? Can we accurately make inferences on a whole species based on fossil samples primarily comprised of isolated teeth? These matters remain to be characterized in a controlled setting. In this study, we tackle this issue from the ground up. A large-scale controlled food trial conducted on domestic sheep provides the framework in which to test these fundamental questions. Our results highlight that analyzing a $200 \times 200 \mu \mathrm{m}$ surface allows for better differentiation between dietary categories, as opposed to analyzing smaller surfaces. Comparisons of facets from upper and lower molars reveal significant variations depending on the contribution to either the buccal or the lingual shearing phase I during the chewing cycle. Investigating the microwear signal along the tooth row does not reveal any significant variation between molars belonging to a same tooth row. However, when simulating three fossil samples composed of isolated upper or lower molars from M1 to M3 from the three sets of ewes, our study does highlight poor results in discriminating dietary categories.
\end{abstract}

Anusha Ramdarshan. Institut de Paléoprimatologie et Paléontologie Humaine: Evolution et Paléoenvironnements UMR 7262 (CNRS and Université de Poitiers), 86073 Poitiers Cedex 9, France. anusha.ramdarshan@univ-poitiers.fr

Cécile Blondel. Institut de Paléoprimatologie et Paléontologie Humaine: Evolution et Paléoenvironnements UMR 7262 (CNRS and Université de Poitiers), 86073 Poitiers Cedex 9, France. cecile.blondel@univpoitiers.fr Denis Gautier. Ferme du Mourier, Institut de l'Elevage, 87800 St Priest Ligoure, France; Centre Interrégional d'Information et de Recherche en Production Ovine, Ferme du Mourier, 87800 Saint Priest

Ramdarshan, Anusha, Blondel, Cécile, Gautier, Denis, Surault, Jérôme, and Merceron, Gildas. 2017. Overcoming sampling issues in dental tribology: Insights from an experimentation on sheep. Palaeontologia Electronica 19.3.53A: 1-19.

https://doi.org/10.26879/762

palaeo-electronica.org/content/2017/2042-what-does-toothwear-represent

Copyright: September 2017 Palaeontology Association.

This is an open access article distributed under the terms of Attribution-NonCommercial-ShareAlike 4.0 International (CC BY-NC-SA 4.0 ), which permits users to copy and redistribute the material in any medium or format, provided it is not used for commercial purposes and the original author and source are credited, with indications if any changes are made.

creativecommons.org/licenses/by-nc-sa/4.0/ 
Ligoure, France. Denis.Gautier@idele.fr

Jérôme Surault. Institut de Paléoprimatologie et Paléontologie Humaine: Evolution et

Paléoenvironnements UMR 7262 (CNRS and Université de Poitiers), 86073 Poitiers Cedex 9, France. jerome.surault@univ-poitiers.fr

Gildas Merceron. Institut de Paléoprimatologie et Paléontologie Humaine: Evolution et

Paléoenvironnements UMR 7262 (CNRS and Université de Poitiers), 86073 Poitiers Cedex 9, France. gildas.merceron@univ-poitiers.fr

Keywords: Dental microwear texture analysis; representativity; mammals; diet; sheep; controlled-foodtesting

Submission: 15 February 2017 Acceptance: 2 October 2017

\section{INTRODUCTION}

The fossil record suffers from its fragmentary nature. The conditions necessary for fossilization are very rarely met, and consequently the fossil record only represents a partial representation of past biodiversity (Foote and Sepkoski, 1999; Benton et al., 2000; Le Fur et al., 2011). Inferences in paleontology, but also disciplines such as paleoecology and paleoanthropology rely on fossil specimens, which can vary in number for a given species from thousands of cranial and post cranial remains to a single isolated tooth. Paleoecology is particularly dependent on this issue. Ecological traits, from diet to ranging behavior, vary between species but also within a given species from population to population. For example, both red deer and roe deer vary significantly in the diet throughout the year (Storms et al., 2008). Some taxa even vary from being grazers for a given season to incorporating a substantial amount of fruit in its diet for another (Gagnon and Chew, 2000). Environment can also be a significant factor influencing diet. For example, impalas (Aepyceros melampus) living in open savanna and grassland landscapes generally eat more grass than their counterparts in savanna woodlands (Codron et al., 2005). Local events with high impact on vegetal resources may also be a major source of dietary variation. For example, in South America, annual flooding forces the red brocket deer (Mazama americana) and the collared peccary (Tayassu tajacu) to retreat to floodplain islands and to shift from a frugivorous to a woody browse diet (Bodmer, 1990). Interpretations in the fossil record are based on specimens which, although belonging to the same locality and possibly the same species, offer no guarantee of originating from the same season or even the same year (or even century) of death. In this con- text, making inferences on a whole species based on a few specimens seems challenging at best.

Among the available paleoecological methods, the analyses of tooth wear at different scales are robust proxies to interpret dietary habits of extinct species in the fossil record. There are two main types of tooth wear, both resulting in the loss of small fragments of enamel from the tooth itself: attrition, the wear resulting from tooth-to-tooth contact, and abrasion, resulting from food-to-tooth contact (Kaiser et al., 2013). Although tooth wear can also have other root causes such as chemical erosion, abrasion is of particular interest in paleoecology as it varies according to the physical properties of the food ingested over the last weeks of an animal's life (Calandra and Merceron, 2016; Merceron et al., 2016; Ramdarshan et al., 2016). Dental microwear texture analysis (DMTA) has now become a widespread tool for reconstructing the past diet of mammals (Ungar, 2015; Calandra and Merceron, 2016; DeSantis, 2016) and even other vertebrates (Purnell et al., 2007; Gill et al., 2014). However, although this method is widely used, few studies have tackled the issue of sample representativity. Can a single scan, representing at best a few hundred square micrometers, give an accurate representation of a whole dental facet, let alone a whole tooth? How does the microwear signal vary along a facet? How large does a scan have to be to provide accurate discrimination between different diets? Answers to these questions are fundamental before reliable dietary interpretations can be given. Microwear is now widely used in paleoecology to reconstruct past diets. However, most studies use whatever material is available: upper, lower, first, second, third molars, and even sometimes premolars are often jumbled together in the same analysis in order to maximize sample size. However, several factors vary along 
the tooth row. For example, the force of the power stroke is known to vary along the tooth row (PérezBarbería and Gordon, 1998, 1999; Radinsky, 1985; von Koenigswald et al., 2013). Efficiency in food comminution depends directly on molar surface occlusal area and contact area (Pérez-Barbería and Gordon, 1998), which varies according to the tooth considered. All foods are not reduced in the same way along the tooth row (Reilly et al., 2001). Furthermore, previous studies (Schulz et al., 2010; Taylor et al., 2013, 2016) have highlighted intertooth differences in several taxa. In these conditions, are the microwear patterns on the first, second and third molars along a same tooth row directly comparable?

These matters remain to be characterized in a controlled setting. In this study, we tackle this issue from the ground up. A large-scale controlled food trial conducted on domestic sheep provides the framework in which to test these fundamental questions. Controlling the physical and mechanical properties of the diet (i.e., toughness, hardness) allows us to characterize the microwear signal. Here, we focus on the questions of scan size representativity, signal variation along the tooth row and between upper and lower cheekteeth (Figure $1)$.

\section{MATERIAL AND METHODS}

\section{Controlled-food Trials}

The controlled-food trials were carried out at the Mourier farm (Limousin region, France; agreement number B-87-176-01), under the supervision of the Centre Interrégional d'Information et de Recherche en Production Ovine (CIIRPO) and the Institut de l'Elevage (Idele; see details in Merceron et al., 2016; Ramdarshan et al., 2016). G.M. and D.G. who have official approval to carry out such procedures, designed these trials. They were performed on domestic sheep (Ovis aries), using only ewes from the Vendéen breed. All experiments were conducted on cull ewes, meaning sheep no longer suitable for breeding and sold for meat. None of the experiments required the sheep to be handled. In this study, all the ewes had been kept in the same pasture highly dominated in grasses for six months before the start of the trials. As such, their dental microwear textures are considered to be homogenous at the beginning of the controlled food testing. Sheep had full access to foods with which they were familiar. The ewes were kept inside a covered sheepfold. The sheep were not kept on hay, which they would have eaten, but on dust-free wood shavings used in equestrian centres. Feeding troughs were covered with a plastic film and cleaned out daily to avoid contamination. None of the ewes lost weight during the experiments (see details in Merceron et al., 2016 and in Ramdarshan et al., 2016).

Thirty sheep were included in this study (Table 1), divided into three groups of ten. Three groups were each given foods with different physical and mechanical properties: soft and silica-depleted browse, tough and silica bearing grass, hard and brittle seeds in complement with soft browse. These qualitative terms are used to broadly qualify the food properties used in this study. Grasses are considered tougher, i.e., to have a higher energy release rate (Berthaume, 2016; Thiery et al., 2017) than browse such as clover. However, we should note that the clover and grass assemblages foraged by the ewes during the experiments do not display any significant differences in fracture toughness (meaning the ability to absorb deformation energy per unit volume before failure) measured thanks to a tensile test (Merceron et al., 2016). Seeds are qualified as hard and brittle as comminution can be obtained through stress created between flat surfaces, as opposed to grasses and browse which require blades to cut through them (Fortelius, 1985). For details on the specific properties of these foods (specific abundance, biosilica content, toughness, hardness), refer to Merceron et al. (2016) and Ramdarshan et al. (2016). The first group of cull ewes was fed on a red clover-dominated silage ( $1.650 \mathrm{~kg}$ per ewe and per day), the second on a multispecific assemblage highly dominated by grasses $(\sim 1.550 \mathrm{~kg}$ per ewe and per day), and the third on the clover-dominated silage ( $1.275 \mathrm{~kg}$ per ewe and per day) in addition with barley kernels ( $0.425 \mathrm{~kg}$ per ewe and per day). The fodders were harvested and then balewrapped 24 hours after the cutting in order to guarantee similar natural physical properties (percentage of dry matter about $50 \%$ ) to the uncut plant throughout the controlled food testing. The ewes had full access to the food. These amounts were defined by giving large amounts of fodder and measuring how much the ewes had consumed in 24 hours. It is worth highlighting that silage tends to be acid and one could hypothesize that differences in dental microwear textures reflects acid erosion rather abrasion or attrition. However, it is known that saliva plays an active role in protecting dental enamel from acid erosion (Hannig and Balz, 1999; Lendenmann et al., 2000; Wetton et al., 2006). 

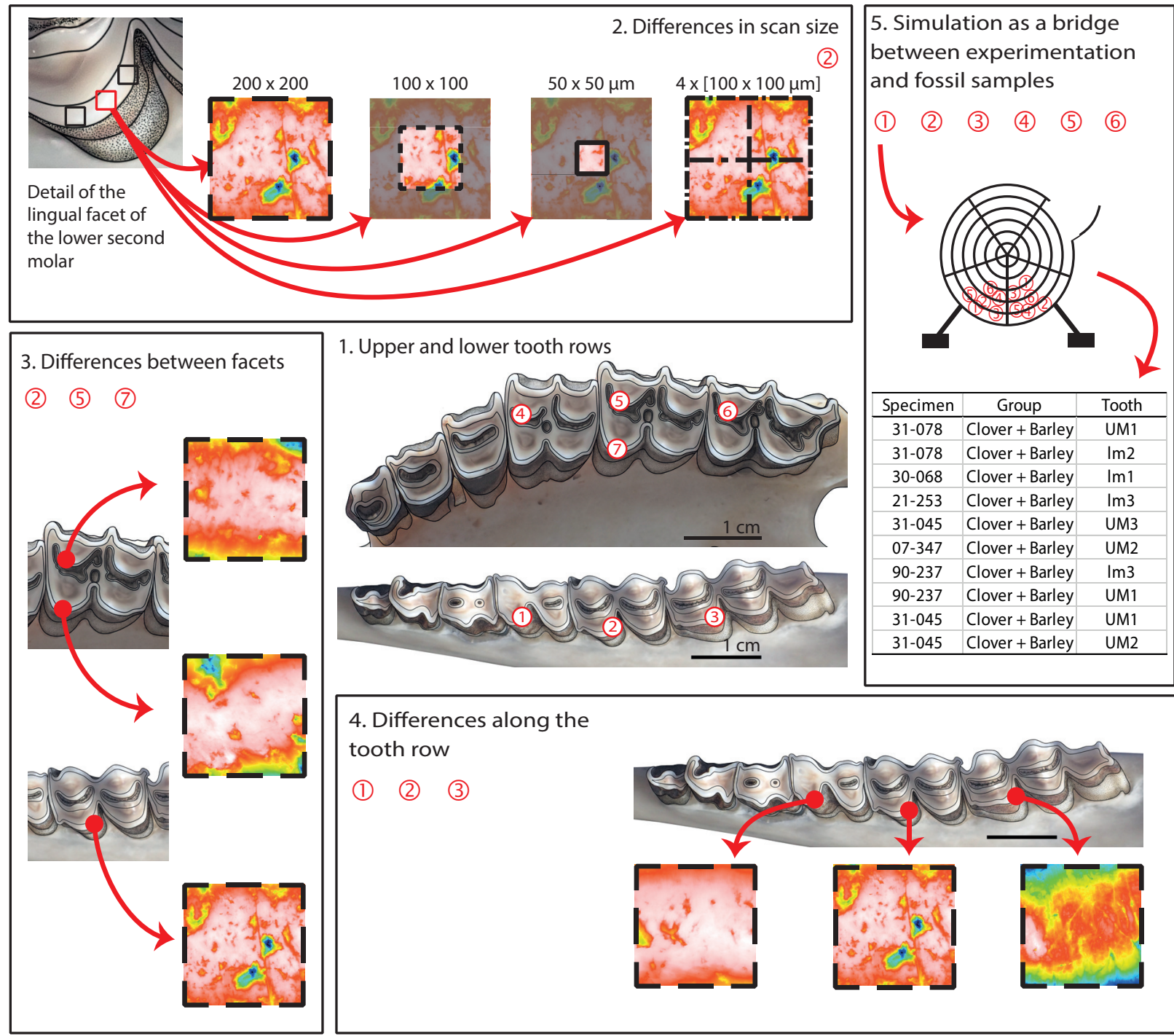

FIGURE 1. Different protocols used in this study. 1, Upper and lower tooth rows of Ovis aries. The red circled numbers 1-7 refer to the facets used in each protocol and are labelled on the maxillary and mandibular tooth rows (1, disto-labial protoconid facet of the first lower molar; 2, disto-labial protoconid facet of the second lower molar; 3 , disto-labial protoconid facet of the third lower molar; 4, mesio-lingual paracone facet of the first upper molar; 5 , mesio-lingual paracone facet of the second upper molar; 6 , mesio-lingual paracone facet of the third upper molar; 7 , mesio-lingual paracone facet of the second upper molar). 2, Differences in scan size: The influence of scan size on the microwear signal is tested by comparing scans of different sizes (illustrated) but from the same central position of the disto-labial protoconid facet (red square). The three squares along the disto-labial protoconid facet indicate the positions used for the 3-spot median. 3, Differences between facets: The homogeneity of the microwear signal between upper and lower molars is tested by comparing lower molars to two different upper molar facets. Red dots highlight the facets which were scanned. Arrows lead to the color-view of the corresponding scan. 4, Differences along the tooth row: the homogeneity of the microwear signal between cheek teeth is tested by comparing first, second and third lowers molars of the same tooth row. Red dots highlight the facets which were scanned. Arrows lead to the color-view of the corresponding scan. 5, Simulation as a bridge between experimentation and fossil samples: Random draw from each 60-observation sample in order to simulate samples with isolated cheekteeth belonging to possibly the same individuals. A 10 observation simulated sample is given here as an example. 
TABLE 1. Mean and standard error for complexity (Asfc) and anisotropy (epLsar) measured on different dental facets of upper (UM) and lower molars (Im) with a $200 \times 200 \mu \mathrm{m}$ scan size.

\begin{tabular}{|c|c|c|c|c|c|c|c|}
\hline \multirow{2}{*}{ Category } & \multirow{2}{*}{ Tooth } & \multirow{2}{*}{ Dental facet } & \multirow{2}{*}{$\mathbf{N}$} & \multicolumn{2}{|c|}{ Asfc } & \multicolumn{2}{|c|}{ epLsar $\left(\times 10^{-3}\right)$} \\
\hline & & & & Mean & SE & Mean & SE \\
\hline \multirow[t]{7}{*}{ Clover } & $\operatorname{Im} 1$ & disto-labial protoconid & 10 & 3.86 & 0.98 & 3.79 & 1.11 \\
\hline & $\operatorname{lm} 2$ & & 10 & 5.43 & 1.10 & 2.17 & 0.55 \\
\hline & $\operatorname{lm} 3$ & & 10 & 4.23 & 0.66 & 2.01 & 0.33 \\
\hline & UM1 & mesio-lingual paracone & 9 & 3.33 & 0.53 & 4.36 & 1.01 \\
\hline & UM2 & & 10 & 2.22 & 0.43 & 1.94 & 0.40 \\
\hline & UM3 & & 8 & 3.60 & 0.70 & 2.58 & 0.61 \\
\hline & UM2 & mesio-lingual protocone & 10 & 4.35 & 1.30 & 3.37 & 0.76 \\
\hline \multirow{7}{*}{$\begin{array}{l}\text { Clover + } \\
\text { Barley }\end{array}$} & $\operatorname{lm} 1$ & disto-labial protoconid & 10 & 2.98 & 0.38 & 2.93 & 0.70 \\
\hline & $\operatorname{lm} 2$ & & 10 & 4.80 & 1.17 & 2.26 & 0.58 \\
\hline & $\operatorname{Im} 3$ & & 9 & 3.93 & 0.95 & 2.37 & 0.61 \\
\hline & UM1 & mesio-lingual paracone & 9 & 4.10 & 0.44 & 4.44 & 1.23 \\
\hline & UM2 & & 10 & 2.78 & 0.43 & 1.90 & 0.64 \\
\hline & UM3 & & 9 & 4.20 & 0.87 & 3.56 & 0.74 \\
\hline & UM2 & mesio-lingual protocone & 10 & 4.57 & 0.42 & 3.52 & 0.86 \\
\hline \multirow[t]{7}{*}{ Grass } & $\operatorname{lm} 1$ & disto-labial protoconid & 10 & 2.40 & 0.41 & 5.70 & 1.07 \\
\hline & $\operatorname{lm} 2$ & & 10 & 3.06 & 0.58 & 4.66 & 1.07 \\
\hline & $\operatorname{lm} 3$ & & 8 & 2.97 & 0.62 & 3.44 & 1.20 \\
\hline & UM1 & mesio-lingual paracone & 10 & 5.69 & 1.43 & 6.52 & 1.26 \\
\hline & UM2 & & 10 & 1.91 & 0.31 & 3.29 & 0.61 \\
\hline & UM3 & & 9 & 3.63 & 0.84 & 5.04 & 0.94 \\
\hline & UM2 & mesio-lingual protocone & 10 & 3.33 & 0.78 & 6.10 & 1.15 \\
\hline
\end{tabular}

\section{Casting and Data Analysis}

The skulls are housed at the iPHEP lab (UMR 7262 CNRS and Université de Poitiers). Each analyzed tooth (first, second, and third upper molars [UM1, UM2, and UM3, respectively] and first, second, and third lower molars [Im1, Im2, and $\operatorname{Im} 3$, respectively]; Figure 1.1) was then carefully cleaned with a cotton-swab soaked in acetone. Molds are then made using a polyvinylsiloxane elastomer (Regular Body President, ref 6015 - ISO 4823, medium consistency, polyvinylsiloxane addition type; Coltene Whaledent). This product is known to be the most efficient one to replicate a given surface (Galbany et al., 2006; Goodall et al., 2015).

The molds are then placed under a Leica DCM8 confocal profilometer using white light confocal technology with a Leica $100 \times$ objective (Numerical aperture $=0.90$; working distance $=0.9$ $\mathrm{mm})$. The lateral resolution is an $(x, y)$ interval of $0.129 \mu \mathrm{m}$, with a vertical numerical step of $1 \mathrm{~nm}$.

The analyses were performed using the Scale-Sensitive Fractal Analysis using Toothfrax and Sfrax software (Surfract, www.surfract.com) following Scott et al. (2006). Complexity (Asfc or Area-scale fractal complexity) is a measure of the roughness at a given scale. Anisotropy (epLsar or exact proportion of length-scale anisotropy of relief) measures the orientation concentration of surface roughness (Table 1; Appendix 1).

Before each sets of statistical tests in this study, data were rank-transformed in order to ensure the conditions for parametric tests were met (Conover and Iman, 1981). Data were then analyzed using two-way repeated measures ANOVAs and corresponding post-hoc tests (Pairwise Student test, performed with the Bonferroni adjustment method to take into account non-independent observations).

\section{Different Case Studies for Different Questions}

Differences in scan size. Dental microwear texture analysis has been highly improved by Scott et al. $(2005,2006)$. Since then the method has been widely used to reconstruct diet in both living and extinct mammals. The standard scan size of 4 adjoining scans of $100 \times 140 \mu \mathrm{m}$ was defined in 
order to match the size used in early studies using SEM. Several studies, carried out on smaller taxa such as rodents or lagomorphs, even use scans as small as $15 \times 15 \mu \mathrm{m}$ (Schulz et al., 2013; Withnell and Ungar, 2014; Burgman et al., 2016; Calandra et al., 2016a, 2016b). Here, we test the representativity of scan size (Figure 1.2). A scan was performed at the central position for each disto-labial protoconid facet of the second lower molar. From this scan several surfaces were treated: $50 \times 50$ $\mu \mathrm{m}, 100 \times 100 \mu \mathrm{m}$, and $200 \times 200 \mu \mathrm{m}$. Each $200 \times$ $200 \mu \mathrm{m}$ scan was also treated as four equal subsurfaces, to test the pertinence to analyze a surface as a whole, or as a combination of subsurfaces as established by Scott et al. (2005, 2006). An additional value, called 3-spot mean, corresponds to the mean of the anisotropy (epLsar) and complexity (Asfc) of three different scans along the facet (i.e., in a buccal, central and lingual position). Three scans along the facet were made in order to test the variation of the microwear signal. Although variations can be seen between the lingual, central, and jugal positions, no significant differences are highlighted by this study (see Appendices 2-3). The mean of the three values (buccal, central, and lingual) is also used to test differences with value gained from scans of different size.

Differences between upper and lower teeth. Numerous microwear studies use both upper and lower molars in order to maximize sample size. The lingual paracone facets and the labial protoconid facets are traditionally used in dental microwear studies (Semprebon et al., 2004; Merceron et al., 2012; Scott, 2012; Rivals et al., 2015) as they occlude during the shearing phase I (Janis, 1979, 1990) and supposedly share similar microwear patterns. Phase $I$ is dominated by shearing actions as opposed to phase II during which grinding actions are more prevalent (Crompton and Hiiemae, 1969; Janis, 1990; Lucas, 2004). Here, we suppose that the paracone first enters in to contact with lingual cuspids on the lower molar at the beginning of phase I, and then with the buccal cuspids as the lower molars move centrally. It results that the facet on paracone traditionally used in microwear studies enters in contact with more enamel facets than the buccal dental facets of the protoconid on lower molars. Here we test the homogeneity of the dental microwear texture between upper and lower second molars issued from the very same individual (Figure 1.2). Alternatively, we also consider lingual protocone facets on upper second molars because in the same way as the buccal facets of the protoconid on lower molars, they occlude with fewer enamel facets from the homologous counterparts (Figure 1.3). All of the comparisons are made with $200 \times 200 \mu \mathrm{m}$ scans performed on the central position along the enamel band.

Differences between cheekteeth along the tooth row. Similarly to upper and lower molars, numerous microwear studies jumble first, second, and third molars together in order to maximize sample size (Merceron et al., 2005a, 2005b, 2012; Ungar et al., 2007, 2016; García-González et al., 2015). Here, we test the homogeneity of the microwear signal along the lower tooth row (Figure 1.4). Each disto-labial protoconid facet of the first, second, and third lower molars was scanned for each ewe. Dental microwear texture analysis is performed on $200 \times 200 \mu \mathrm{m}$ surfaces.

\section{Simulation as Bridge Between Experimentation and Fossil Samples}

In this study, we will test what the signal carried by a fossil sample really means. Most microwear studies utilize associated dentitions where the specific locus of the tooth sampled is known and pseudoreplication of individuals is absent or minimal (Scott, 2012; Scott et al., 2012; Merceron et al., 2014). However, many have to contend with isolated teeth implying that one individual could be represented several times in one sample (Merceron et al., 2012; Tütken et al., 2013; Oliver Pérez et al., 2014). Does regrouping first, second, and third lower with upper molars as paleontologists used to do reinforce or weaken ecological interpretations compared with analysis run on a single tooth type (e.g., second lower molar)? To answer this question, each disto-labial protoconid facet on lower molars or each mesio-lingual paracone facet on upper molars were scanned (Figure 1). Complexity (Asfc) and Anisotropy (epLsar) were calculated for each scan. This results in a dataset with 60 observations (UM1-3 and Im1-3) for a 10ewe sample. The ewes considered in this study have different ages, and so some individuals do not have a fully erupted third molar. However, they are considered in the datasets so the observation they represent is associated with no values for the two textural parameters.

In order to simulate samples with isolated cheekteeth belonging to possibly the same individuals, three sets of 10,20 , or 30 observations are drawn randomly from each 60-observation sample (grass, clover, and clover/barley; Figure 1.5). This process is repeated a thousand times to generate a significant amount out of possible cases. As stud- 
TABLE 2. Two-way repeated measures ANOVA on complexity (Asfc) and on anisotropy (epLsar) between dietary groups and according to scan options on the disto-labial protoconid facet of the second lower molar.

\begin{tabular}{lccccc}
\hline \multicolumn{1}{c}{ Source of Variance } & Df & Sum Sq & Mean Sq & F Value & Pr(>F) \\
\hline Asfc & 2 & 18078 & 9039 & 2.338 & 0.116 \\
Group & 27 & 104409 & 3867 & & 0.054 \\
Subjects within group & 3 & 1652 & 550.8 & 2.656 & 0.031 \\
Scan options & 6 & 3054 & 509 & 2.455 & 0.072 \\
Group $\times$ Scan options & 81 & 16797 & 207.4 & & 0.122 \\
Scan options $\times$ Subjects & & & & & 0.466 \\
within group & 2 & 20718 & 10359 & 2.905 & \\
epLsar & 27 & 96272 & 3566 & & \\
Group & 3 & 1738 & 579.4 & 0.947 & \\
Subjects within group & 6 & 1656 & 276 & & \\
Scan options & 81 & 23606 & 291.4 & & \\
Group $\times$ Scan options & & & & & \\
Scan options $\times$ Subjects & & & & & \\
within group & & & & & \\
\hline
\end{tabular}

ies on fossil specimens have to primarily contend with isolated teeth with no indication as to whether or not they belong to the same individual, no precaution is taken here to avoid sampling multiple observations from the same individual (although the random sampling is without replacement). The result is a dataset with three groups (grass, clover, and clover/barley) containing 10,20 , or 30 observations each.

For each of the thousand iterations, data are rank transformed to ensure the conditions to carry out parametric statistical tests are met. As we are considering datasets as we would in the fossil sample, single classification ANOVAs (and not repeated measures) are then performed to highlight any significant differences between clover-, grass-, and clover/barley-fed ewes. Results are reported as the frequency of significant $p$-values over the 1000 iterations.

\section{RESULTS AND DISCUSSION}

\section{Scan Mode and Size on Lower Molar}

The two-way repeated measure ANOVA shows significant variations in complexity (Asfc) between scan options (marginally with $p=0.054$; Table 2) with a significant effect of the interaction between scan option and dietary groups (Figure 2). The two-way repeated measure ANOVA also shows marginal variations in anisotropy (epLsar) between dietary groups. The pairwise post-hoc comparisons highlight significant differences in complexity (Asfc) and anisotropy (epLsar) between the three different dietary groups for all scan size options except for the 3-spot mean (Tables 1 and 3 ; Figure 2). Indeed, there is no significant difference between the different dietary groups of ewes when several scans at different position along a facet are considered. To multiply scans over a dental facet, instead of focusing on a scan at the central position, blurs the differences between groups.

When looking at the different scans from 200 to $50 \mu \mathrm{m}$ a side, differences between diets depend on which scan size is considered. Results at 200 $\mu \mathrm{m}, 100 \mu \mathrm{m}$, and $50 \mu \mathrm{m}$ all show significant differences between the clover-fed and grass-fed samples for Asfc (Table 3). None highlight differences in complexity (Asfc, Tables 2 and 3, Figure 2) between the clover/barley-fed ewes and the two other groups. Using the 4-subsurface median option, differences in complexity are significant between clover-fed and grass-fed ewes, but again none between the clover/barley fed ewes and the two other groups (Table 3 ).

Results for anisotropy (epLsar) are more varied. Results at $50 \mu \mathrm{m}$ do not show any significant differences between groups (Table 3 ). This result may seem counterintuitive given the very different means of each group. Actually, the high inter-individual differences in anisotropy (and complexity as well) due to the random occurrence of a given microwear feature (such as deep overlapping pits with complex slopes) and thus high variance (Figure 2) in each group is such that there is a major overlap between all the groups, preventing the repeated measures ANOVA from highlighting any potential difference in microwear textures. This result would seem to indicate that looking through 


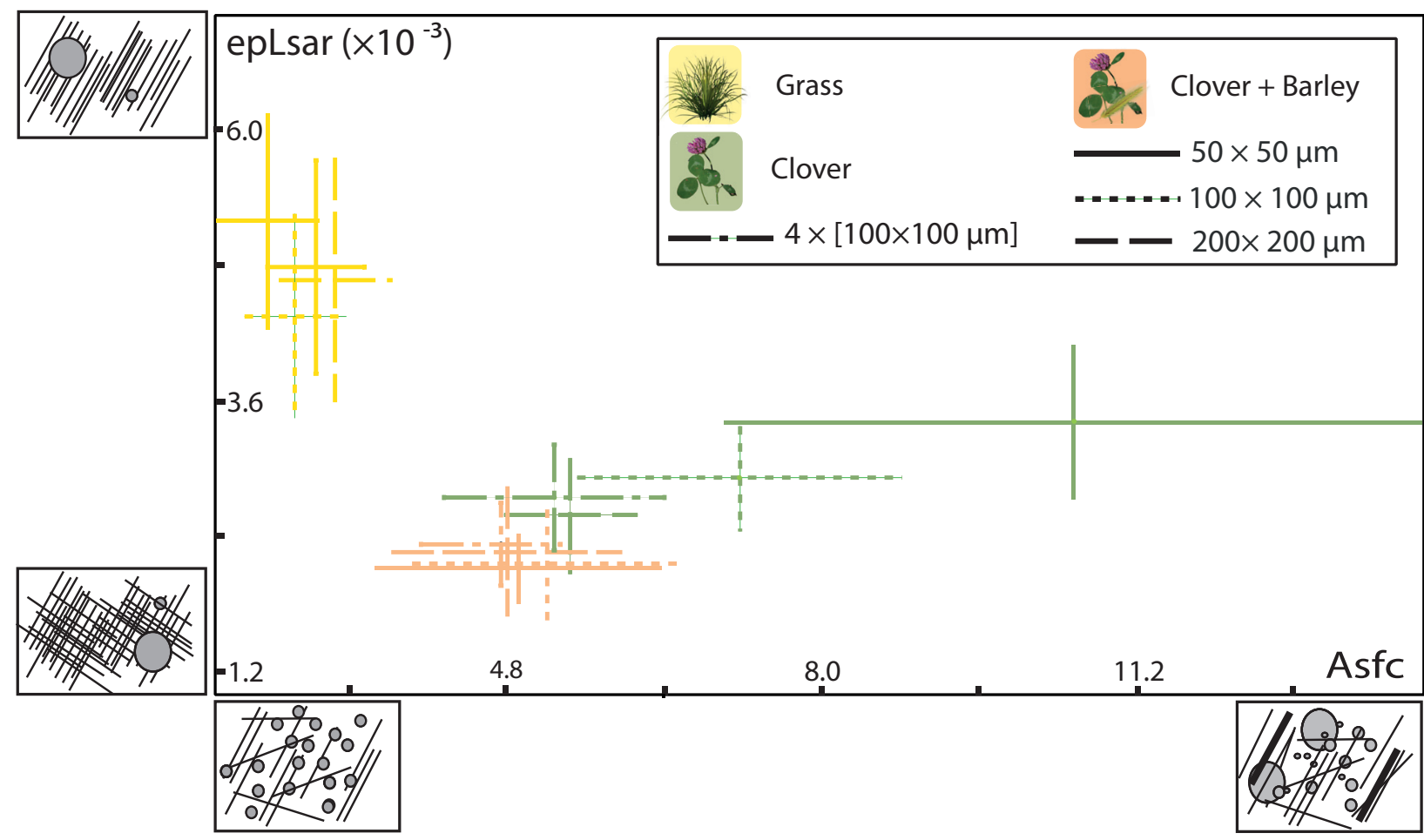

FIGURE 2. Mean and standard error of the mean for complexity (Asfc) and anisotropy (epLsar) of the dental microwear textures for each ewe sample and for different scan options. The four boxes are schematic representations of enamel surfaces with varying microwear textures (high/low epLsar and high/low Asfc).

a $50 \mu \mathrm{m}$ window for large mammals is indeed not wide enough to be able to see the whole picture. At $100 \mu \mathrm{m}$ a side, only the clover/barley-fed ewes show any significant difference in anisotropy (epLsar) from the grass-fed ewes (Tables 1 and 3). No difference between clover and grass fed ewes are found at this scale. Both the epLsar at $200 \mu \mathrm{m}$ a side and the 4-subsurface median option show differences between clover/barley and grass fed ewes, and between clover and grass fed ewes. Furthermore, using the traditional median of four adjoining scans does not provide any additional information compared to using a $200 \times 200 \mu \mathrm{m}$ square. As such, a $200 \times 200 \mu \mathrm{m}$ seems more pertinent for future dental microwear texture analysis. This study, carried out on domestic sheep, does carry implications for other taxa, notably in ruminants. When considering applications beyond the model organism, other factors need to be taken into account. A $200 \times 200 \mu \mathrm{m}$ surface might not be available in some taxa, or differences in masticatory cycles might produce peculiar microwear patterns in others. However, these results suggest that scan size can be a limiting factor when trying to highlight differences in diet.

\section{Differences Between Facets from Upper and Lower Teeth}

The two-way repeated measures ANOVA highlights significant variations in Asfc between upper and lower molars when the disto-labial protoconid and mesio-lingual paracone facets are considered (Tables 1 and 4). Disto-labial protoconid facets show more complex surfaces than the mesio-lingual paracone ones (Tables 1, 4, 5, Figure 3). Dietary differences between the ewe samples are more pronounced when considering the disto-labial protoconid facets of the lower molars (Tables 1, 4, 6; Figure 3).

When using a repeated measures ANOVA, there is no significant variation in Asfc when the disto-labial protoconid and mesio-lingual protocone facets are considered (Tables 1 and 7; Figure 3). The repeated measures ANOVA does highlight significant variations in epLsar between the different dietary groups and between facets. However, further analysis pinpointing the latter differences show that they are not between upper and lower molars of the same dietary category (Table 8).

These results highlight the importance in dental microwear analysis to pinpoint dental facets at a broad scale and to consider their precise function(s) that intervene during the masticatory cycle 
TABLE 3. Post hoc pairwise comparisons on complexity (Asfc) and on anisotropy (epLsar) between dietary groups and according to scan options on the disto-labial protoconid facet of the second lower molar. Scan options are as follows: central position scans with $50 \times 50,100 \times 100$, or $200 \times 200 \mu \mathrm{m}$ size, 4-subsurface median option refers to the median value of four $100 \times 100 \mu \mathrm{m}$ surface sampled within the $200 \times 200 \mu \mathrm{m}$ scan on the central position along the dental facet and the 3-spot mean refers the mean values for three $200 \times 200 \mu \mathrm{m}$ scans sampled from the labial to central to lingual positions along the tooth facet.

\begin{tabular}{|c|c|c|c|c|c|c|}
\hline \multirow[b]{2}{*}{ 3-spot mean } & \multicolumn{3}{|c|}{ Asfc } & \multicolumn{3}{|c|}{ epLsar } \\
\hline & Clover & Clover + Barley & Grass & Clover & Clover + Barley & Grass \\
\hline Clover & - & - & - & - & - & - \\
\hline Clover + Barley & 0.338 & - & - & 0.924 & - & - \\
\hline Grass & 0.213 & 0.08 & - & 0.053 & 0.064 & - \\
\hline $200 \times 200 \mu \mathrm{m}$ & Clover & Clover + Barley & Grass & Clover & Clover + Barley & Grass \\
\hline Clover & - & - & - & - & - & - \\
\hline Clover + Barley & 0.458 & - & - & 0.648 & - & - \\
\hline Grass & 0.018 & 0.296 & - & 0.006 & 0.022 & - \\
\hline $100 \times 100 \mu \mathrm{m}$ & Clover & Clover + Barley & Grass & Clover & Clover + Barley & Grass \\
\hline Clover & - & - & - & - & - & - \\
\hline Clover + Barley & 0.324 & - & - & 0.061 & - & - \\
\hline Grass & 0.008 & 0.096 & - & 0.209 & 0.043 & - \\
\hline 4-subsurface median & Clover & Clover + Barley & Grass & Clover & Clover + Barley & Grass \\
\hline Clover & - & - & - & - & - & - \\
\hline Clover + Barley & 0.504 & - & - & 0.26 & - & - \\
\hline Grass & 0.007 & 0.253 & - & 0.017 & 0.025 & - \\
\hline $50 \times 50 \mu \mathrm{m}$ & Clover & Clover + Barley & Grass & Clover & Clover + Barley & Grass \\
\hline Clover & - & - & - & - & - & - \\
\hline Clover + Barley & 0.094 & - & - & 0.212 & - & - \\
\hline Grass & 0.028 & 0.149 & - & 0.123 & 0.068 & - \\
\hline
\end{tabular}

TABLE 4. Two-way repeated measures ANOVA on complexity (Asfc) and on anisotropy (epLsar) between dietary groups and between upper and lower teeth (mesio-lingual facet of the paracone and disto-labial facet of the protoconid).

\begin{tabular}{|c|c|c|c|c|c|}
\hline Source of Variance & Df & Sum Sq & Mean Sq & F Value & $\operatorname{Pr}(>F)$ \\
\hline \multicolumn{6}{|l|}{ Asfc } \\
\hline Group & 2 & 975 & 487.6 & 2.759 & 0.081 \\
\hline Subjects within group & 27 & 4772 & 176.7 & & \\
\hline Tooth & 1 & 2587 & 2587.3 & 7.651 & 0.01 \\
\hline Group $\times$ Tooth & 2 & 531 & 265.4 & 0.785 & 0.466 \\
\hline Tooth $\times$ Subjects within group & 27 & 9130 & 338.1 & & \\
\hline \multicolumn{6}{|l|}{ epLsar } \\
\hline Group & 2 & 2818 & 1408.8 & 3.954 & 0.031 \\
\hline Subjects within group & 27 & 9619 & 356.3 & & \\
\hline Tooth & 1 & 209 & 209.07 & 1.059 & 0.313 \\
\hline Group $\times$ Tooth & 2 & 20 & 9.82 & 0.05 & 0.952 \\
\hline Tooth $\times$ Subjects within group & 27 & 5329 & 197.38 & & \\
\hline
\end{tabular}



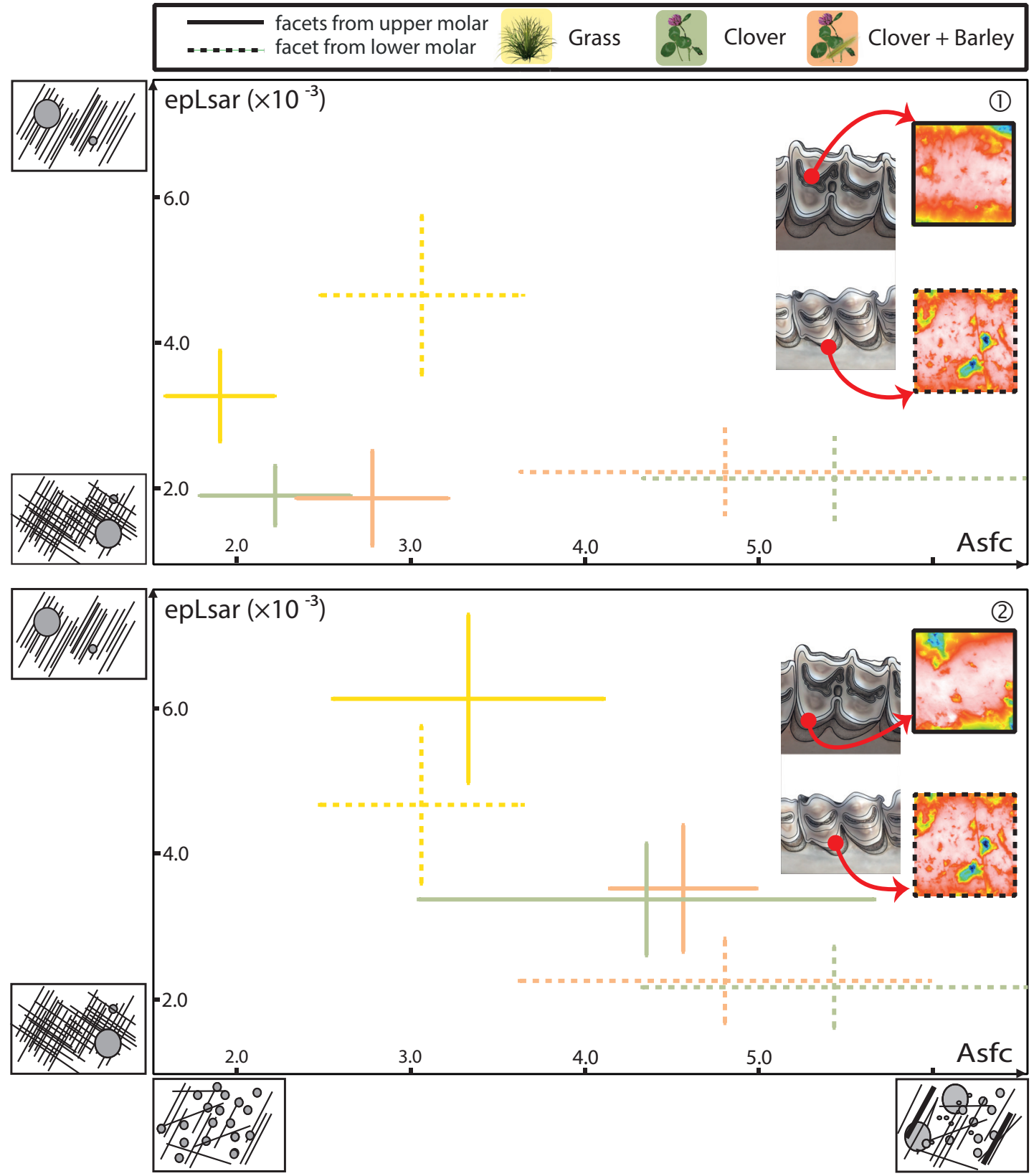

FIGURE 3. Mean and standard error of the mean for complexity (Asfc) and anisotropy (epLsar) of the dental microwear textures for dental facets from upper and lower molars and for each dietary sample. 1, Comparison of the disto-labial protoconid facet of the second lower molar and the mesio-lingual paracone facet of the second upper molar. 2, Comparison of the disto-labial protoconid facet of the second lower molar and mesio-lingual protocone facet of the second upper molar.

(buccal and lingual shearing in phase I) before running any micrometric-scale analysis.

\section{Differences Between Cheekteeth Along the Tooth Row}

A two-way repeated measures ANOVA was carried out on first, second, and third lower molars in order to highlight potential differences between groups (Table 9, Figure 4). However, this analysis fails to show any significant variations in complexity (Asfc), suggesting that there is minimal variation along the tooth row. The study does highlight differences in anisotropy (epLsar). However, further investigation using post-hoc multicomparison tests reveal that first, second, and third molars of the same dietary category do not differ significantly from one another (Table 10). The only differences shown by the post-hoc tests are in fact between 
TABLE 5. Post-hoc pairwise comparisons on complexity (Asfc) between dietary groups and between upper and lower teeth (mesio-lingual facet of the paracone and disto-labial facet of the protoconid).

\begin{tabular}{ccccc}
\hline & & \multicolumn{3}{c}{ Upper molars } \\
& & Clover & $\begin{array}{c}\text { Clover } \\
\text { Barley }\end{array}$ & Grass \\
\hline Lower & Clover & 0.018 & - & - \\
molars & Clover + Barley & - & 0.362 & - \\
& Grass & - & - & 0.287 \\
\hline
\end{tabular}

different dietary categories (Table 10). Again, this result suggests that there is little variation in the microwear textures along the tooth row in a given dietary category.

The results in this study fail to highlight differences in microwear texture between the different cheek teeth on the lower left jaw. This would seem to indicate that microwear textures are relatively homogenous along the tooth row. Simply put, microwear is a direct reflection of how food is reduced. This simple notion means that microwear depends on numerous factors such as the size, shape, and material properties of food particles, the size, shape, material properties of teeth, occlusal forces, vectors, and more (Lucas, 2004). In these conditions one expectation would be that microwear textures show significant differences between different teeth from the same tooth row. Our results indicate this is not the case. The lack of variations in dental microwear textures along the tooth row could mean that the power stroke, even if maximum at a given point along the tooth row, would see its force homogenously distributed due to the tooth row acting as a geometric plane (in ruminants compared to carnivorous mammals with molar shape heterogeneity).

\section{Simulating a Fossil Sample}

The lack of any significant differences between teeth from the same tooth row suggests that dietary differences will still be able to be highlighted when using first, second, and third molars together. We have also highlighted the misuse of

TABLE 6. Post-hoc pairwise comparisons on anisotropy (epLsar) between dietary groups and between upper and lower teeth (mesio-lingual facet of the paracone and disto-labial facet of the protoconid).

\begin{tabular}{|c|c|c|c|c|c|c|c|}
\hline & & \multicolumn{3}{|c|}{ Upper molars } & \multicolumn{3}{|c|}{ Lower molars } \\
\hline & & Clover & Clover + Barley & Grass & Clover & Clover + Barley & Grass \\
\hline \multirow{3}{*}{$\begin{array}{l}\text { Lower } \\
\text { molars }\end{array}$} & Clover & 0.780 & - & - & & & \\
\hline & Clover + Barley & - & 0.155 & - & 0.891 & & \\
\hline & Grass & - & - & 0.580 & 0.003 & 0.036 & \\
\hline \multirow{3}{*}{$\begin{array}{l}\text { Upper } \\
\text { molars }\end{array}$} & Clover & & & & & & \\
\hline & Clover + Barley & 0.679 & & & & & \\
\hline & Grass & 0.137 & 0.008 & & & & \\
\hline
\end{tabular}

TABLE 7. Two-way repeated measures ANOVA on complexity (Asfc) and on anisotropy (epLsar) between dietary groups and between upper and lower teeth (lingual facet of the protocone and disto-labial protoconid facets respectively).

\begin{tabular}{|c|c|c|c|c|c|}
\hline Source of Variance & Df & Sum Sq & Mean Sq & F Value & $\operatorname{Pr}(>\mathrm{F})$ \\
\hline \multicolumn{6}{|l|}{ Asfc } \\
\hline Group & 2 & 1333 & 666.7 & 1.904 & 0.169 \\
\hline Subjects within group & 27 & 9456 & 350.2 & & \\
\hline Tooth & 1 & 15 & 15 & 0.061 & 0.807 \\
\hline Group $\times$ Tooth & 2 & 553 & 276.4 & 1.124 & 0.34 \\
\hline Tooth $\times$ Subjects within group & 27 & 6638 & 245.9 & & \\
\hline \multicolumn{6}{|l|}{ epLsar } \\
\hline Group & 2 & 2696 & 1348 & 4.162 & 0.027 \\
\hline Subjects within group & 27 & 8744 & 323.9 & & \\
\hline Tooth & 1 & 1144 & 1144.1 & 5.722 & 0.024 \\
\hline Group $\times$ Tooth & 2 & 12 & 5.8 & 0.029 & 0.971 \\
\hline Tooth $\times$ Subjects within group & 27 & 5399 & 199.9 & & \\
\hline
\end{tabular}


TABLE 8. Post-hoc pairwise comparisons on complexity (Asfc) and on anisotropy (epLsar) between dietary groups and between upper and lower teeth (lingual facet of the protocone and disto-labial protoconid facets, respectively).

\begin{tabular}{llccc}
\hline & Clover & $\begin{array}{r}\text { Upper molars } \\
\text { Clover + Barley }\end{array}$ & Grass \\
\hline Lower molars & Asfc & 0.336 & - & - \\
& Clover & - & 0.409 & - \\
& Clover + Barley & - & - & 0.954 \\
& Grass & & & \\
& & & - & - \\
& epLsar & & & - \\
& Clover & 0.3209 & 0.1363 & 0.0854 \\
\hline & - & - & \\
& Clover + Barley & - &
\end{tabular}

TABLE 9. One-way repeated measures ANOVAs on each diet categories on Asfc and epLsar between dietary groups and between first, second, and third lower molars (disto-labial protoconid facets).

\begin{tabular}{|c|c|c|c|c|c|}
\hline Source of Variance & Df & Sum Sq & Mean Sq & F Value & $\operatorname{Pr}(>\mathrm{F})$ \\
\hline \multicolumn{6}{|l|}{ Asfc } \\
\hline Group & 2 & 2606 & 1303 & 1.753 & 0.192 \\
\hline Subjects within group & 27 & 20070 & 743.3 & & \\
\hline Tooth & 2 & 2493 & 1246.3 & 1.923 & 0.156 \\
\hline Group $\times$ Tooth & 4 & 585 & 146.1 & 0.226 & 0.923 \\
\hline Tooth $\times$ Subjects within group & 54 & 34990 & 648 & & \\
\hline \multicolumn{6}{|l|}{ epLsar } \\
\hline Group & 2 & 7200 & 3600 & 5.24 & 0.012 \\
\hline Subjects within group & 27 & 18552 & 687 & & \\
\hline Tooth & 2 & 1938 & 969 & 1.61 & 0.209 \\
\hline Group $\times$ Tooth & 4 & 553 & 138.3 & 0.23 & 0.921 \\
\hline Tooth $\times$ Subjects within group & 54 & 32499 & 601.8 & & \\
\hline
\end{tabular}

the combination of upper and lower dental facets, assumed to be homologous (or antagonist sensu Schultz et al., 2017) because occluding during the dental shearing phase I (Janis, 1990), but actually involved in different ways during the phase I. Thus, here, we investigated the effects of grouping altogether these two types of dental facets from upper and lower molars, a habit widely used by paleoecologists to increase sample size and supposedly strengthen their analysis.

To test this hypothesis, we simulated fossil samples using a random sampling (see Material and Methods; Appendix 4). Results for the simulation of a fossil sample are summarized in Table 11 and Figure 5. These results are detailed in Appendices 5-10. Complexity (Asfc) and anisotropy (epLsar) for each dietary group and for each iteration are presented in Appendices 5-7. The frequency with which significant differences are highlighted vary according to the number of simulated individu- als per group. When considering $n=10$, significant differences are highlighted in only $7.1 \%$ (Asfc) and $25.6 \%$ (epLsar) of the 1000 iterations. Frequencies are higher when considering 20 individuals per group $(8.7 \%$ and $46.6 \%$, respectively) and highest when considering 30 individuals per group $(10 \%$ and $72.1 \%$, respectively).

Our results suggest that combining dental microwear textures on disto-labial facets on protoconid of first, second, and third lower molars together with the textural parameters from the mesio-lingual facets on upper molars increases the sample variance to the point of hiding any differences between dietary categories. Numerous studies base their microwear results on data including significant amount of isolated, determined, or undetermined teeth, jumbled together to maximize sample size (Ungar et al., 2007; Merceron et al., 2012; Tütken et al., 2013). Our results indicate that this practice does not help gain statistical strength. 


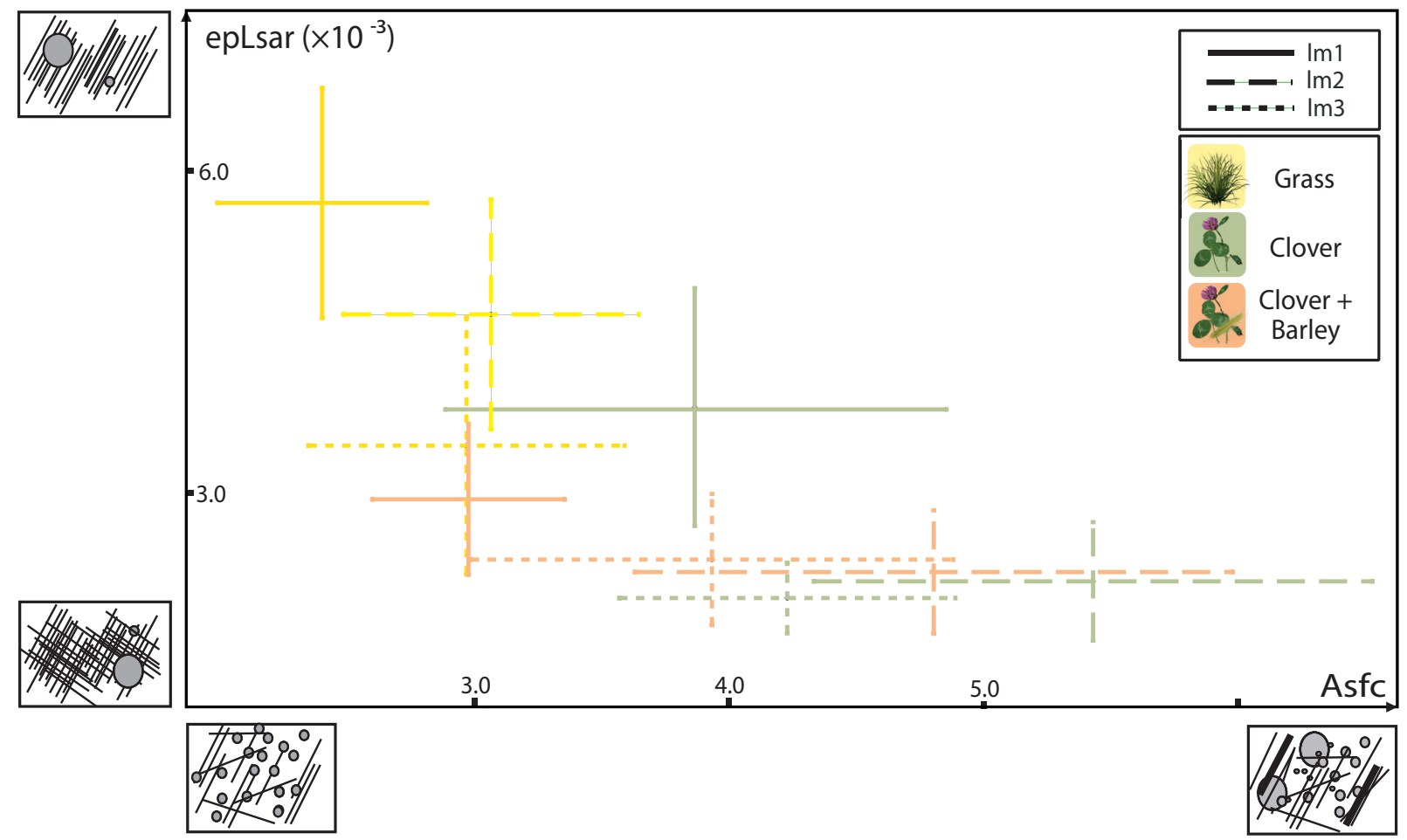

FIGURE 4. Mean and standard error of the mean for complexity (Asfc) and anisotropy (epLsar) of the dental microwear textures for each ewe sample and for each molar of the tooth row.

TABLE 10. Post-hoc pairwise comparisons on anisotropy (epLsar) between dietary groups and between first, second, and third lower molars (disto-labial protoconid facets). Results for complexity (Asfc) are not shown here as the one-way repeated measures ANOVAs did not yield significant $p$-values.

\begin{tabular}{|c|c|c|c|c|c|c|c|c|c|}
\hline & & \multicolumn{3}{|c|}{ Clover } & \multicolumn{3}{|c|}{ Clover + Barley } & \multicolumn{2}{|c|}{ Grass } \\
\hline & & $\operatorname{Im} 1$ & Im2 & $\operatorname{lm} 3$ & $\operatorname{Im} 1$ & Im2 & $\operatorname{lm} 3$ & Im1 & Im2 \\
\hline \multirow[t]{2}{*}{ Clover } & $\operatorname{Im} 2$ & 0.395 & - & - & - & - & - & - & - \\
\hline & $\operatorname{Im} 3$ & 0.384 & 0.948 & - & - & - & - & - & - \\
\hline \multirow{3}{*}{$\begin{array}{c}\text { Clover + } \\
\text { Barley }\end{array}$} & $\operatorname{lm} 1$ & 0.716 & - & - & - & - & - & - & - \\
\hline & $\operatorname{Im} 2$ & - & 0.706 & - & 0.155 & - & - & - & - \\
\hline & $\operatorname{Im} 3$ & - & - & 0.769 & 0.900 & 0.563 & - & - & - \\
\hline \multirow[t]{3}{*}{ Grass } & $\operatorname{lm} 1$ & 0.051 & - & - & 0.002 & - & - & - & - \\
\hline & $\operatorname{Im} 2$ & - & 0.038 & - & - & 0.031 & - & 0.157 & - \\
\hline & $\operatorname{Im} 3$ & - & - & 0.220 & - & - & 0.504 & 0.236 & 0.784 \\
\hline
\end{tabular}

TABLE 11. Summary of the ANOVA results carried out on 1000 iterations. Results reported as the frequency of significant differences in complexity (AsfC) and anisotropy (epLsar) over 1000 iterations when comparing the three simulated groups (based on grass, clover, and clover/barley-fed ewes, respectively) for samples comprised of 10 , 20, or 30 values per samples.

\begin{tabular}{ccc}
\hline Simulation & \multicolumn{2}{c}{$\begin{array}{c}\text { Frequency (Pval < 0.05) } \\
\text { epLsar }\end{array}$} \\
\hline $\mathrm{n}=10$ & $7.1 \%$ & $25.6 \%$ \\
$\mathrm{n}=20$ & $8.7 \%$ & $46.6 \%$ \\
$\mathrm{n}=30$ & $10.0 \%$ & $72.1 \%$ \\
\hline
\end{tabular}



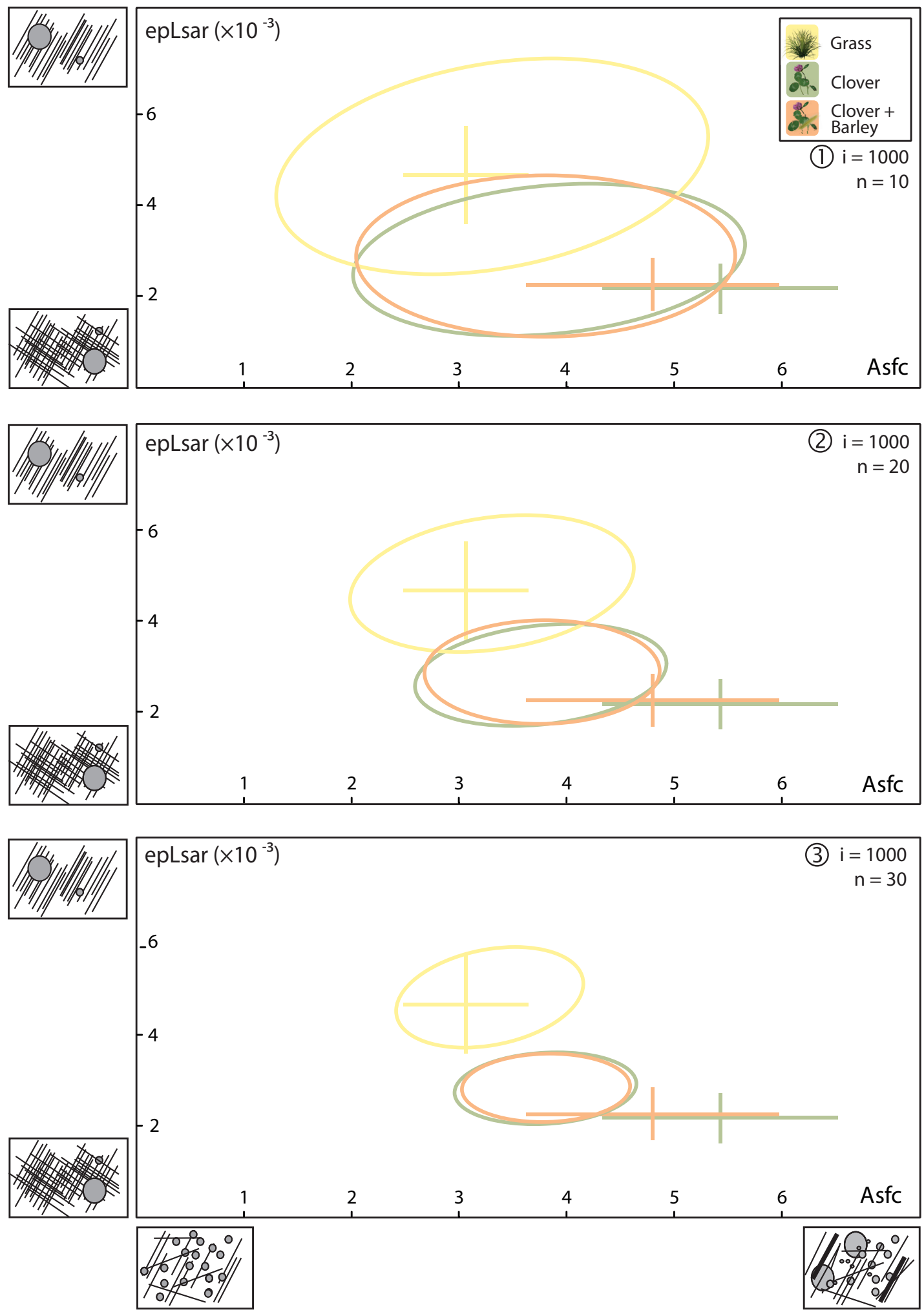

FIGURE 5. Mean and standard error of the mean for complexity (Asfc) and anisotropy (epLsar) of the dental microwear textures for the simulations of fossil data using random sampling of the ewe dataset. Ellipses represent $95 \%$ of the means for each iteration. Mean and standard error of the mean for each sample (lower second molars) are also represented for comparison. 1, Simulation with 10 individuals per dietary category and 1000 iterations. 2, Simulation with 20 individuals per dietary category and 1000 iterations. 3, Simulation with 30 individuals per dietary category and 1000 iterations. 
Such practices could therefore result in artificially inflating the mixed feeding groups to the detriment of the grazing and browsing ends of the dietary spectrum among herbivorous mammals.

Another factor which seems to influence the results is sample size. Indeed, in this simulation, the highest frequency with which significant differences are highlighted is when $\mathrm{N}=30$. Increasing sample size does seem to reduce variance and therefore the overlap between dietary categories. However, while this did increase efficiency for anisotropy (epLsar), this was not the case for complexity (Asfc). Even when $\mathrm{N}=30$, differences in Asfc are only significant in $10 \%$ of the 1000 iterations. This result would seem to indicate that strengthening sample size by itself is not sufficient, but that it also needs to be combined with a strict protocol focused on a specific tooth locus.

\section{CONCLUSIONS}

By controlling the dietary breadth of three different groups of ewes, this study tackles fundamental issues in the field of dental microwear texture analysis such as scan size, differences between teeth of a same tooth row, or differences between differences dental facets from upper and lower teeth. Our results have shown than a scan of $200 \times 200 \mu \mathrm{m}$ provides the best results in order to discriminate between different dietary categories, and provides the same information as using the median of 4-subsurfaces, as used in many previous studies. Furthermore, results allowed for a direct comparison of microwear textures between teeth from a same tooth row. No significant differences could be shown by this study. Differences were, however, highlighted between previously considered homologous facets in upper and lower teeth, highlighting the importance to split dental facets depending on their function during the chewing cycle, even within the two buccal and lingual shearing phases during phase $\mathrm{I}$. We overcome this issue by identifying dental facets from upper and lower molars that indeed share the same functions during the lingual shearing phase I and thus similar textures on enamel surfaces. Finally, the ewe dataset is used to simulate the characteristics of a fossil sample. We show that the common practices of combining isolated determined and undetermined upper and lower molars (especially using inappropriate dental facets) resulted in a loss of ecological discrimination at a population scale, but also at the level of species and communities through space and time. To track environmental changes in the fossil record requires us to indeed strengthen the protocol rather than the sample size.

\section{ACKNOWLEDGMENTS}

The authors thank the staff from the Mourier Farm Station, E. Pottier (IDELE), B. Grillon, J.-M. Grolleau (Limovin), F. Vannier (President of the CIIRPO), J. Merceron (Director of the IDELE), as well as G. Reynaud (iPHEP). The authors thank N. Brunetière and $A$. Francisco ( $P$ prime Institute, CNRS, ENSMA, and University of Poitiers), two members of the TRIDENT project team. We are also grateful to editors of $\mathrm{PE}$ and anonymous reviewers that improved the manuscript by all of their comments. This study was financed by the Project ANR TRIDENT (ANR-13-JSV7-0008-01, PI: G. Merceron).

\section{REFERENCES}

Benton, M.J., Wills, M.A., and Hitchin, R. 2000. Quality of the fossil record through time. Nature, 403:534537.

Berthaume, M.A. 2016. Food mechanical properties and dietary ecology. American Journal of Physical Anthropology, 159:79-104.

Bodmer, R.E. 1990. Responses of ungulates to seasonal inundations in the Amazon floodplain. Journal of Tropical Ecology, 6:191-201.

Burgman, J.H., Leichliter, J., Avenant, N.L., and Ungar, P.S. 2016. Dental microwear of sympatric rodent species sampled across habitats in southern Africa: Implications for environmental influence. Integrative Zoology, 11:111-127.

Calandra, I., Labonne, G., Schulz-Kornas, E., Kaiser, T.M., and Montuire, S. 2016a. Tooth wear as a means to quantify intra-specific variations in diet and chewing movements. Scientific Reports, 6:34037.

Calandra, I., Zub, K., Szafrańska, P.A., Zalewski, A., and Merceron, G. 2016b. Silicon-based plant defences, tooth wear and voles. Journal of Experimental Biology, 219:501-507.

Calandra, I. and Merceron, G. 2016. Dental microwear texture analysis in mammalian ecology. Mammal Review, 46:215-228.

Codron, D., Codron, J., Lee-Thorp, J.A., Sponheimer, M., De Ruiter, D., and Brink, J.S. 2005. Dietary variation in Impala Aepyceros melampus recorded by carbon isotope composition of feces. Acta Zoologica Sinica, 52:1015-1025.

Conover, W.J. and Iman, R.L. 1981. Rank transformations as a bridge between parametric and nonparametric statistics. American Statistician, 35:124-129.

Crompton, A.W. and Hiiemae, K. 1969. How mammalian molar teeth work. Discovery, 5:23-34.

DeSantis, L.R.G. 2016. Dental microwear textures: reconstructing diets of fossil mammals. Surface Topography: Metrology and Properties, 4:023002. 
Foote, M. and Sepkoski, J.J. 1999. Absolute measures of the completeness of the fossil record. Nature, 398:415-417

Fortelius, M. 1985. Ungulate cheek teeth: Developmental, functional, and evolutionary interrelations. Acta Zoologica Fennica, 180:1-76.

Gagnon, M. and Chew, A.E. 2000. Dietary preferences in extant African Bovidae. Journal of Mammalogy, 8:490-511.

Galbany, J., Estebaranz, F., Martínez, L.M., Romero, A., De Juan, J., Turbón, D., and Pérez-Pérez, A. 2006. Comparative analysis of dental enamel polyvinylsiloxane impression and polyurethane casting methods for SEM research. Microscopy Research and Technique, 69:246-252.

García-González, R., Carretero, J.M., Richards, M.P., Rodríguez, L., and Quam, R. 2015. Dietary inferences through dental microwear and isotope analyses of the Lower Magdalenian individual from El Mirón Cave (Cantabria, Spain). Journal of Archaeological Science, 60:28-38.

Gill, P.G., Purnell, M.A., Crumpton, N., Brown, K.R., Gostling, N.J., Stampanoni, M., and Rayfield, E.J. 2014. Dietary specializations and diversity in feeding ecology of the earliest stem mammals. Nature, 512:303-305.

Goodall, R.H., Darras, L.P., and Purnell, M.A. 2015. Accuracy and precision of silicon based impression media for quantitative areal texture analysis. Scientific Reports, 5:10800.

Hannig, M. and Balz, M. 1999. Influence of in vivo formed salivary pellicle on enamel erosion. Caries Research, 33:372-379.

Janis, C.M. 1979. Mastication in the hyrax and its relevance to ungulate dental evolution. Paleobiology, 5:50-59.

Janis, C.M. 1990. The correlation between diet and dental wear in herbivorous mammals, and its relationship to the determination of diets of extinct species, $p$. 241-259. In Boucot, A.J. (ed.), Evolutionary Paleobiology of Behavior and Coevolution. Elsevier, Amsterdam.

Kaiser, T.M., Müller, D.W.H., Fortelius, M., Schulz, E., Codron, D., and Clauss, M. 2013. Hypsodonty and tooth facet development in relation to diet and habitat in herbivorous ungulates: Implications for understanding tooth wear. Mammal Review, 43:34-46.

Le Fur, S., Fara, E., and Vignaud, P. 2011. Effect of simulated faunal impoverishment and mixture on the ecological structure of modern mammal faunas: Implications for the reconstruction of Mio-Pliocene African palaeoenvironments. Palaeogeography, Palaeoclimatology, Palaeoecology, 305:295-309.

Lendenmann, U., Grogan, J., and Oppenheim, F.G. 2000. Saliva and dental pellicle-a review. Advances in Dental Research, 14:22-28.

Lucas, P.W. 2004. Dental Functional Morphology: How Teeth Work. Cambridge University Press, Cambridge.
Merceron, G., Blondel, C., Bonis, L. de, Koufos, G.D., and Viriot, L. 2005a. A new dental microwear analysis: application to extant Primates and Ouranopithecus macedoniensis (Late Miocene of Greece). Palaios, 20:551-561.

Merceron, G., Bonis, L. de, Viriot, L., and Blondel, C. 2005b. Dental microwear of the Late Miocene bovids of Northern Greece: The Vallesian/Turolian environmental changes as explanation of the disappearance of Ouranopithecus macedoniensis? Bulletin de la Société Géologique de France, 176:475-484.

Merceron, G., Costeur, L., Maridet, O., Ramdarshan, A., and Göhlich, U.B. 2012. Multi-proxy approach detects heterogeneous habitats for primates during the Miocene climatic optimum in Central Europe. Journal of Human Evolution, 63:150-161.

Merceron, G., Hofman-Kamińska, E., and Kowalczyk, R. 2014. 3D dental microwear texture analysis of feeding habits of sympatric ruminants in the Białowieża Primeval Forest, Poland. Forest Ecology and Management, 328:262-269.

Merceron, G., Ramdarshan, A., Blondel, C., Boisserie, J.-R., Brunetiere, N., Francisco, A., Gautier, D., Milhet, X., Novello, A., and Pret, D. 2016. Untangling the environmental from the dietary: Dust does not matter. Proceeding Royal Society of London, series B, 283:20161032.

Oliver Pérez, A., Hernández Vallarín, V., López Guerrero, P., García Paredes, I., Álvarez Sierra, M.Á., Gómez Cano, A.R., García Yelo, A.B., Alcalde Rincón, G.M., and Peláez-Campomanes de Labra, P. 2014. Dental microwear analysis in Gliridae (Rodentia): Methodological issues and paleodiet inferences based on Armantomys from the Madrid Basin (Spain). Journal of Iberian Geology, 40:157-166.

Pérez-Barbería, F.J. and Gordon, I.J. 1998. Factors affecting food comminution during chewing in ruminants: A review. Biological Journal of the Linnean Society, 63:233-256.

Pérez-Barbería, F.J. and Gordon, I.J. 1999. The functional relationship between feeding type and jaw and cranial morphology in ungulates. Oecologia, 118:157-165.

Purnell, M.A., Bell, M.A., Baines, D.C., Hart, P.J.B., and Travis, M.P. 2007. Correlated evolution and dietary change in fossil Stickleback. Science, 317:1887.

Radinsky, L. 1985. Patterns in the evolution of ungulate jaw shape. American Zoologist, 25:303-314.

Ramdarshan, A., Blondel, C., Brunetière, N., Francisco, A., Gautier, D., Surault, J., and Merceron, G. 2016. Seeds, browse, and tooth wear: A sheep perspective. Ecology and Evolution, 6:5559-5569.

Reilly, S.M., McBrayer, L.D., and White, T.D. 2001. Prey processing in amniotes: Biomechanical and behavioral patterns of food reduction. Comparative Biochemistry and Physiology Part A: Molecular \& Integrative Physiology, 128:397-415.

Rivals, F., Prignano, L., Semprebon, G.M., and Lozano, S. 2015. A tool for determining duration of mortality 
events in archaeological assemblages using extant ungulate microwear. Scientific Reports, 5:17330.

Schultz, J.A., Menz, U., Winkler, D.E., Schulz-Kornas, E., Engels, S., Kalthoff, D.C., von Koenigswald, W., Ruf, I., Kaiser, T.M., Kullmer, O., and others. 2017. Modular wear facet nomenclature for mammalian post-canine dentitions. Historical Biology, 1-12.

Schulz, E., Calandra, I., and Kaiser, T.M. 2010. Applying Tribology to Teeth of Hoofed Mammals. Scanning, 32:162-182.

Schulz, E., Piotrowski, V., Clauss, M., Mau, M., Merceron, G., and Kaiser, T.M. 2013. Dietary abrasiveness is associated with variability of microwear and dental surface texture in rabbits. PLOS ONE, 8:e56167.

Scott, J.R. 2012. Dental microwear texture analysis of extant African Bovidae. Mammalia, 76:157-174.

Scott, R.S., Teaford, M.F., and Ungar, P.S. 2012. Dental microwear texture and anthropoid diets. American Journal of Physical Anthropology, 147:551-579.

Scott, R.S., Ungar, P., Bergstrom, T.S., Brown, C.A., Childs, B.E., Teaford, M.F., and Walker, A. 2006. Dental microwear texture analysis: Technical considerations. Journal of Human Evolution, 51:339-349.

Scott, R.S., Ungar, P.S., Bergstrom, T.S., Brown, C.A., Grine, F.E., Teaford, M.F., and Walker, A. 2005. Dental microwear texture analysis shows within-species diet variability in fossil hominins. Nature, 436:693695.

Semprebon, G.M., Godfrey, L.R., Solounias, N., Sutherland, M.R., and Jungers, W.L. 2004. Can low-magnification stereomicroscopy reveal diet? Journal of Human Evolution, 47:115-144.

Storms, D., Aubry, P., Hamann, J.-L., Saïd, S., Fritz, H., Saint-Andrieux, C., and Klein, F. 2008. Seasonal variation in diet composition and similarity of sympatric red deer Cervus elaphus and roe deer Capreolus capreolus. Wildlife Biology, 14:237-250.

Taylor, L.A., Kaiser, T.M., Schwitzer, C., Müller, D.W., Codron, D., Clauss, M., and Schulz, E. 2013. Detect- ing inter-cusp and inter-tooth wear patterns in rhinocerotids. PLoS ONE, 8:e80921.

Taylor, L.A., Müller, D.W.H., Schwitzer, C., Kaiser, T.M., Castell, J.C., Clauss, M., and Schulz-Kornas, E. 2016. Comparative analyses of tooth wear in freeranging and captive wild equids. Equine Veterinary Journal, 48:240-245.

Thiery, G., Guy, F., and Lazzari, V. 2017. Investigating the dental toolkit of primates based on food mechanical properties: Feeding action does matter. American Journal of Primatology, 79: e22640

Tütken, T., Kaiser, T.M., Vennemann, T., and Merceron, G. 2013. Opportunistic feeding strategy for the earliest old world hypsodont equids: Evidence from stable isotope and dental wear proxies. PLOS ONE, 8:e74463.

Ungar, P.S. 2015. Mammalian dental function and wear: A review. Biosurface and Biotribology, 1:25-41.

Ungar, P.S., Scott, J.R., and Steininger, C.M. 2016. Dental microwear differences between eastern and southern African fossil bovids and hominins. South African Journal of Science, 112:1-5.

Ungar, P.S., Merceron, G., and Scott, R.S. 2007. Dental microwear texture analysis of Varswater bovids and early Pliocene paleoenvironments of Langebaanweg, Western Cape Province, South Africa. Journal of Mammalian Evolution, 14:163-181.

von Koenigswald, W., Anders, U., Engels, S., Schultz, J.A., and Kullmer, O. 2013. Jaw movement in fossil mammals: Analysis, description and visualization. Paläontologische Zeitschrift, 87:141-159.

Wetton, S., Hughes, J., West, N., and Addy, M. 2006. Exposure time of enamel and dentine to saliva for protection against erosion: A study in vitro. Caries Research, 40:213-217.

Withnell, C.B. and Ungar, P.S. 2014. A preliminary analysis of dental microwear as a proxy for diet and habitat in shrews. Mammalia, 78:409-415. 


\section{APPENDIX 1.}

Anisotropy and complexity for each ewe and for each case study. See palaeo-electronica.org/ content/2017/2042-what-does-toothwear-represent for zipped PDF of Appendices.

\section{APPENDIX 2.}

Two-way repeated measures ANOVA on Asfc and epLsar between dietary groups and between different positions on the shearing facet. Significant $p$-values are highlighted in bold. See palaeoelectronica.org/content/2017/2042-what-does-toothwear-represent for zipped PDF of Appendices.

\section{APPENDIX 3.}

Two-way repeated measures ANOVA on Asfc and epLsar between dietary groups and between different positions on the shearing facet. Significant $p$-values are highlighted in bold. See palaeoelectronica.org/content/2017/2042-what-does-toothwear-represent for zipped PDF of Appendices.

\section{APPENDIX 4.}

Example of a randomized dataset simulating a fossil sample for which all molar positions are considered. Complexity (Asfc) and anisotropy (epLsar) are measured on disto-labial protoconid facets on lower molars and mesiolingual paracone facets on upper molars. See palaeo-electronica.org/content/2017/2042-what-does-toothwear-represent for zipped PDF of Appendices.

\section{APPENDIX 5.}

Means of complexity (Asfc) and anisotropy (epLsar) for the three simulated dietary groups (with $n=10$ ) for each of 1000 iterations (see material and methods for details). See palaeo-electronica.org/content/2017/2042-what-does-toothwear-represent for zipped PDF of Appendices.

\section{APPENDIX 6.}

Means of complexity (Asfc) and anisotropy (epLsar) for the three simulated dietary groups (with $n=20$ ) for each of 1000 iterations (see material and methods for details). See palaeo-electronica.org/content/2017/2042-what-does-toothwear-represent for zipped PDF of Appendices.

\section{APPENDIX 7.}

Means of complexity (Asfc) and anisotropy (epLsar) for the three simulated dietary groups (with $n=30$ ) for each of 1000 iterations (see Material and Methods for details). See palaeo-electronica.org/content/2017/2042-what-does-toothwear-represent for zipped PDF of Appendices.

\section{APPENDIX 8.}

Differences between the three dietary groups for each of the 1000 iterations and for $\mathrm{N}=10$ are explored through ANOVAs after rank transformation of the data. See palaeo-electronica.org/content/2017/2042-what-does-toothwear-represent for zipped PDF of Appendices. 


\section{APPENDIX 9.}

Differences between the three dietary groups for each of the 1000 iterations and for $N=20$ are explored through ANOVAs after rank transformation of the data. See palaeo-electronica.org/content/2017/2042-what-does-toothwear-represent for zipped PDF of Appendices.

\section{APPENDIX 10.}

Differences between the three dietary groups for each of the 1000 iterations and for $\mathrm{N}=30$ are explored through ANOVAs after rank transformation of the data. See palaeo-electronica.org/content/2017/2042-what-does-toothwear-represent for zipped PDF of Appendices. 